\title{
Design and Development of Internet of Things Based Smart Ration Dispensing System
}

\author{
C P Mallikarjuna Gowda, Raju Hajare, Shubha V Jois, Pavana, Srinivas M
}

\begin{abstract}
In this paper, we proposed a smart IOT based automated Public ration dispensing system that overcomes the major challenges present in the existing Public Distribution System (PDS) which are irregular measurement of goods, erroneous entries in the stock register of centres containing incorrect stock information of the commodities that are delivered to the consumers, this results in inaccurate distribution of the goods to the beneficiary. We overcome those drawbacks by incorporating smart measuring automated electronic device which authenticate user, measures the goods accurately, updates it in data base periodically about the availability of goods, and thereby digitizing the dispense tracking, which improves the transparency of the PDS.
\end{abstract}

Keywords- Automation, Digitization, Database management, Authentication.

\section{INTRODUCTION}

Public distribution system (PDS) is one of the most prominent provisioning systems in this nation. This PDS is recognized by the Government of India subordinate Ministry of Consumer Affairs, Food and Public Distribution. The fair price shops are mainly used to distribute the goods at a cost lower than that of the market rates or at absolutely no cost. The Indian food security system was established by the Government of India under the Ministry of Consumer Affairs, Food and Public Distribution to ration out food items, non-food items and other commodities to the economically weaker sections of the Indian population. This scheme was first initiated in February 1944, around the time of the Second World War, and was launched properly in the

Revised Manuscript Received on February 05, 2020.

* Correspondence Author

C P Mallikarjuna Gowda, Department of Electronics and Telecommunication Engineering, BMS Institute of Technology and Management, Visvesvaraya Technological University, Bengaluru, India. Email: cpmallikarjunagowda@bmsit.in

Raju Hajare, Department of Electronics and Telecommunication Engineering, BMS Institute of Technology and Management, Visvesvaraya Technological University, Bengaluru, India. Email: rajuhajare@bmsit.in

Shubha V Jois, Department of Electronics and Telecommunication Engineering, BMS Institute of Technology and Management, Visvesvaraya Technological University, Bengaluru, India.

Pavana, Department of Electronics and Telecommunication Engineering, BMS Institute of Technology and Management, Visvesvaraya Technological University, Bengaluru, India.

Srinivas M, Department of Electronics and Telecommunication Engineering, BMS Institute of Technology and Management, Visvesvaraya Technological University, Bengaluru, India.

(c) The Authors. Published by Blue Eyes Intelligence Engineering and Sciences Publication (BEIESP). This is an open access article under the CC BY-NC-ND license (http://creativecommons.org/licenses/by-nc-nd/4.0/) current form in June 1947. Major commodities distributed include staple food grains, such as wheat, rice, sugar and vegetable oils etc. through a network of fair price shops (also known as ration shops) established in several states across the country. Earlier there was a provision to distribute fuels such as kerosene which was used by rural and some urban households but now it has stopped. When it comes to the magnitude, coverage and the budget/expenditure it is considered to be very massive and important. However, it can be seen and has been observed that the food grains supplied at ration shops are of inferior quality or do not satisfy the needs of the community. The average level of consumption of PDS seeds in India is only $1 \mathrm{~kg}$ per person per month. The PDS has been heavily mocked for its urban bias and its failure to serve the economically deprived parts of community with any proper effect. The targeted PDS is costly and gives rise to a lot of room for corruption and other illegal practices in the process of extricating from the poor to serve the needs of the less needy. The Fair Price shops in India are presently known to distribute a wide variety of items ranging from rice grains, wheat, vegetable oil to other commodities like soap, laundry detergent etc. The ration distribution system is revamped and made automated by the usage of an embedded system technology. This automated ration system replaces the conventional ration card system which was completely manual by the use of a biometric scanner as in [2]. The finger print module is placed in the system in order to check the correct user access and then authentication of the user takes place. Once the user has been authenticated and checked to be true with the pre-existing database we can move on to the next step of dispensing ration. There is an attached weighing system so that accurate weighing of the ration dispensing takes place to prevent any spillage or wastage which is made possible by the use of load cells as in [4-5]. There is also an online database that is maintained as mentioned earlier to ease the process of record keeping and to prevent anyone tampering with it along with a provision to receive an acknowledgement for the ration delivery timings and notifications [6]. Information and the fingerprint impression of the eligible user from a particular family are stored securely in the database whose access is only available to the government or the organization maintaining the process of record keeping. Once the appropriate and authentic information is updated it is obtained by automated ration system concerning the existing subsidies for after the information is read the ration is dispensed according to what that user is entitled to on the database information. This also depends heavily on the availability of the product in the inventory at any given time. 
After every transaction made by the beneficiary, the main database is updated and he/she will be sent a SMS (Short Message Service) specifying the quantity of whatever ration has been dispensed to him/her [8]. The present PDS works in a multiple level where the responsibilities are shared between centre and state. The task of procuring food grains at minimal cost is the responsibilities of the centre.

Allocation of the grains to each state is also another task carried out by the centre. Finally, the state government is responsible for carrying out the field work and surveys to identify the households eligible for ration.

The process runs as follows with the grains transported by the centre to every state's central depot and after that they are delivered to the fair price shops. Finally, FPS being the end point rations out the commodities. In the existing system, tasks like ration dispensation, Ration Card entry, product weighing and delivery of the product are carried out manually by someone who is physically present at the shop like an employee of the FPS. However, the present system has diverse drawbacks involved. Some of the irregularities include replacing actual products dispensed by the government with meagre quality products. We also see that a lot of the food grains are diverted by the FPS owners to the open markets for more profits. False entries in the stock registers that FPS agent needs to maintain are also made.

The paper is organised in the following sequence: Related works are investigated in Section II. Section III comprises of problem statement and objectives. In Section IV, we propose our method, followed by the results in section VI and conclusion of our work in Section VII. Finally, section VIII consists of future scope followed by references.

\section{Motivation:}

The current system in the PDS incorporates manual work that creates numerous problems for the government as well as the customers. Therefore, a new approach is required. The key things which played major role in taking up this project are as follows:

1. A technological advancement in electronics and digital payment age.

2. Importance given to the automatic and smart system approach in India.

3. Time factor, i.e. shops not being opened and long queues. Both contributing to slow transaction and paper trail of record keeping.

4. The deceitful dealers who sell subsidized product to unregistered ration card holders and thereby making money out of it.

\section{RELATED WORKS}

The NITI Aayog Development Monitoring and Evaluation Office annually publishes a report [1] for statistical purposes as well as serves as a reference for the budget needs for future and projected success failure of existing yojanas of the government. For the measurement of liquid, the models proposed by M. Pallikonda Rajesekaran, et al., [2] is considered in this paper. The liquid flow rate is calculated by the procedure given in paper [3] proposed by Vishnu R. Kale et al. Shubham Mahesh Wari et al., [4] proposed RFID cards for authentication and OTP for security of user which is incorporated in our proposed system. An OTP is sent to user with the help of GSM (SIM900C). The database is managed using MSSQL DBMS. ARM7 microcontroller i.e. LPC2148 (works on 32-bit ARM instruction set), which is low power and supports inherently GSM module and other serial port attachments without the need of any extra analogue parts. In this paper we have used a notification system using GSM module (SIM900C) rather than just OTP and biometric sensor (Fingerprint module) is used for security purposes [5-6]. The model explained in [6] by Sana A. Qader Perampall, et al is used as reference to the project for smart automation of commodities. Technological advancement for the present infrastructure is the major need in all the reports and surveys which are referred to in these papers and the cause of malnourishment, poverty, existing corruption all can be bypassed using automation. They also depict a smart automated system which includes usage of stepper \& DC motors to cut down inaccuracies and user authentication tools i.e. fingerprint sensor and GSM module to prevent fraud activity. The utilization of RFID for authentication procedure and GSM module for notification is given in [7-9] for various applications. The paper [8] by R. Ramani and AKLA focuses the use of RFID and GSM module in the ration dispensing system. The RFID authentication is replaced with Biometric authentication like finger print in the proposed system [10-15] by Swathi R, AKLA.

\section{PROBLEM STATEMENT AND OBJECTIVES}

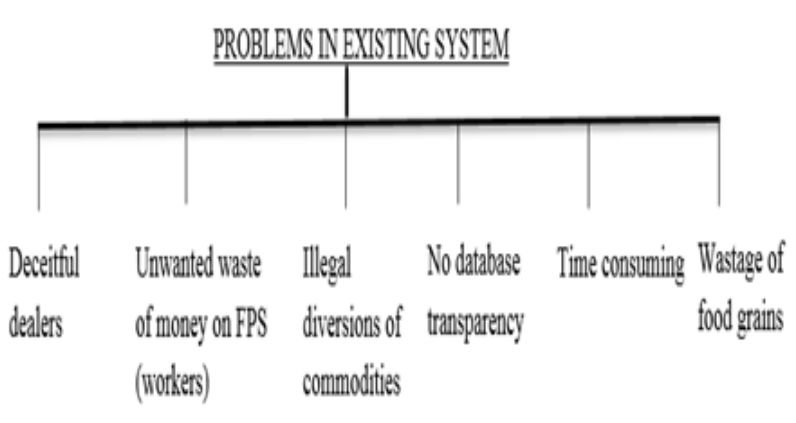

Fig.1 Problems in current PDS

The present functioning Public distribution system has various limitations. One of the major drawbacks is that the entitled person will not receive the entire sanctioned number of commodities. This situation occurs due to the diversion of the commodities by the Fair Price Shop (FPS) owner and middleman to open market for more profit due to this there will be a shortage in the quantity of the commodities. So, the needy will not receive the exact quantity. The classical method involves customer to tell the person handling the ration shop outlet, the amount of the commodity he/she needs and the type too. The person working then measures the commodity and gives it to the customer. Database opacity is the added problem.

The objectives of our work are:

1. Design and analyse the accuracy of material to dispense, real-time database management and alerts to FPS and client using GSM module.

2. To incorporate a biometric identification module (fingerprint sensor) in the system for verification and transparency. 
3. Notification to the user and the FPS owner about the amount dispensed, accurate human interface using keypad for input and LCD display for output.

\section{PRESENT WORK}

The model starts by the fingerprint authentication by using the biometric module. The user scans the finger with the fingerprint sensor and if the id is present, then the program proceeds with the password matched. If the password or fingerprint is not a match, then the program relays back to the initial position of scanning the fingerprint.

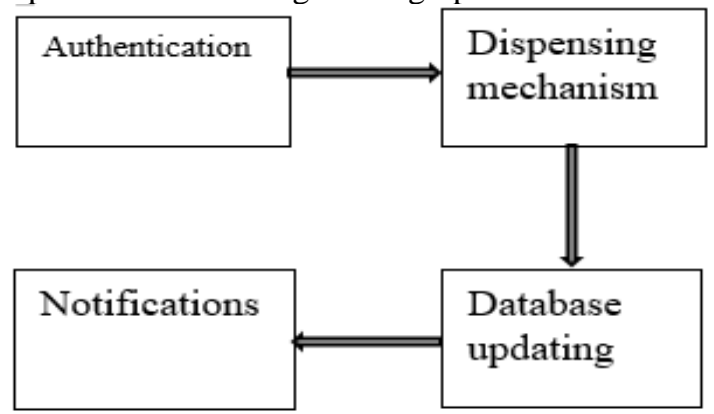

Fig.2 Flow of control block diagram

Then the control is given to the dispensing mechanism where the user is asked to select the type of the material wheat or rice, which is entered through the keyboard. Further the quantity is asked $80 / 100 / 120 \mathrm{gms}$. After selection of quantity the dispensing mechanism using stepper motor and delivery tunnel begins. The ration material is collected in the plastic bowl attached to the load cell and DC motor. When the load is matched, the feedback shuts down the stepper motor and DC motor rotates to the side by an angle of 90 degrees to empty the plastic bowl into the consumer utensil. A webpage is developed to digitalize the transactions and for ease of access to details regarding the commodities allocated to the user. The user will be required to authenticate his identity using the username and password provided. After the authentication process the user can have access to the updated data of the system.

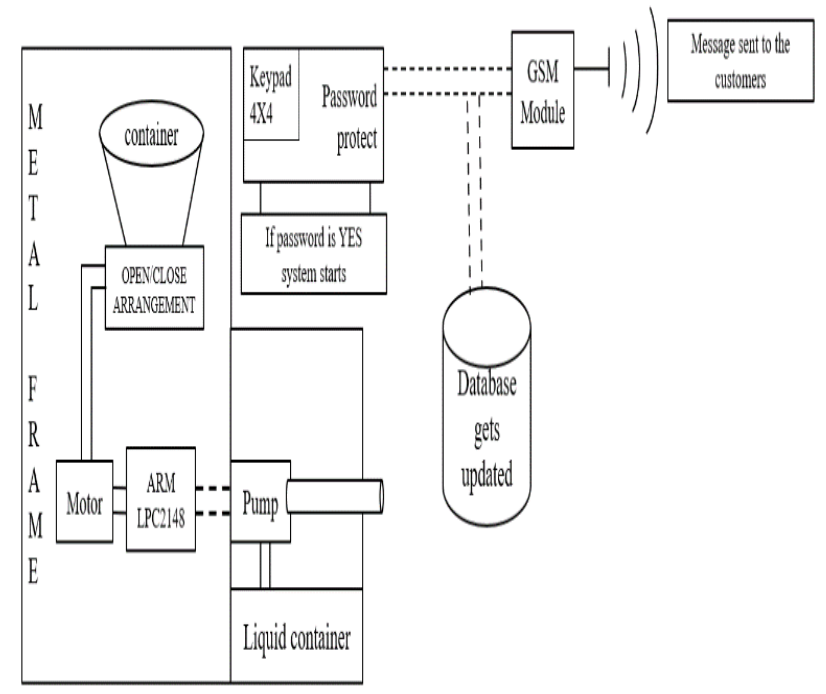

Fig.3 System Block diagram

The webpage has a database updation page consisting of the balance and distribution details of the commodities. The page is constantly updated in real time as transactions occur to show the balance quantity. Another page to maintain the ID number, names, email, phone and place of residence of the list of individuals. A verification SMS is sent to the user with the help of GSM module attached. Giving information about the amount dispensed. The flowchart depicting the system working is shown below:

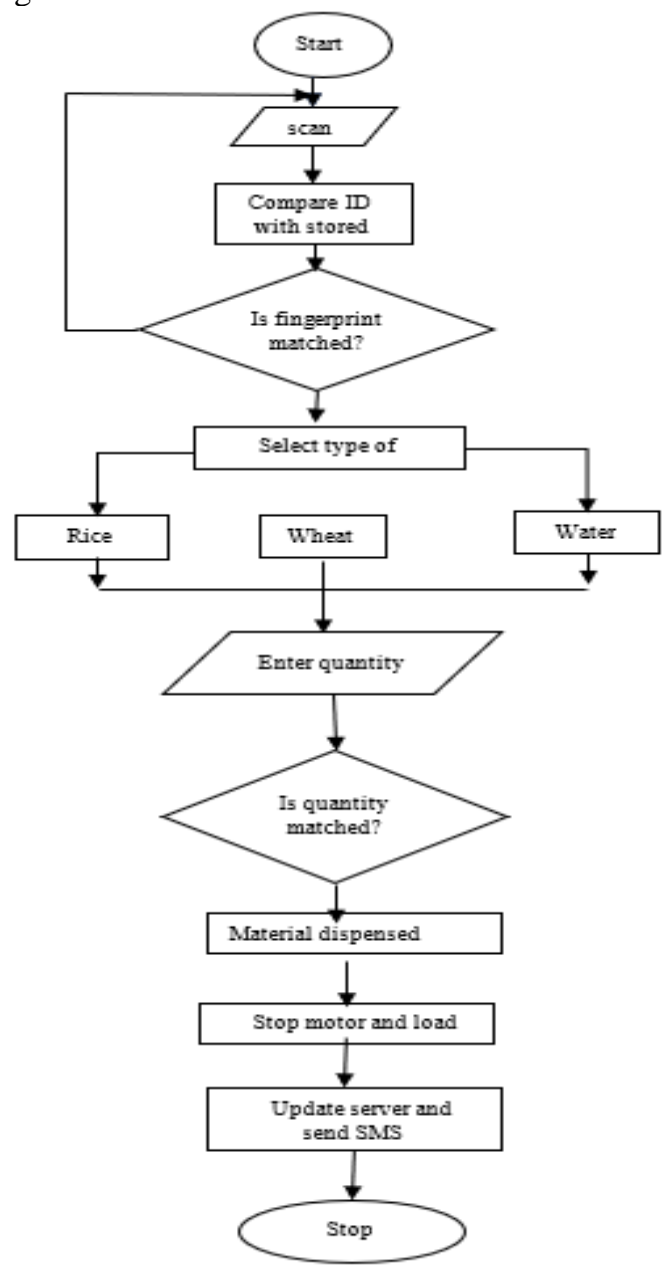

Fig.4 Flowchart of system working

The design is made up of two funnel-shaped valves for wheat and rice which leads to the dispensing unit which has a plastic bowl for the collection of ration materials. The plastic cup then tilts to a tray for the customer to collect the chosen materials. The circuit interfacing consists of ARM LPC2148, GSM module, fingerprint sensor, MAX232 UART, LCD display and Load cell with DC motor attached. GPIO pins P0.0 to P0.15 are used for LCD display (data lines) TX, RX lines of fingerprint sensor, load cell and read/write pins of each are connected to the TX/RX of the ARM microcontroller. The load cell is attached to the DC motor which after feedback from it rotates back and forth 90 degrees with a delay of $50 \mathrm{~ms}$.

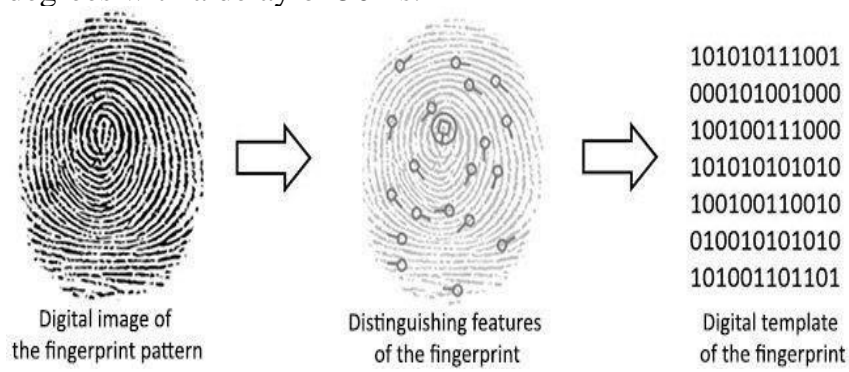

Fig. 5 Working of Fingerprint sensor

Published By: 
The digital image of the fingerprint pattern is captured and the image is known as a live scan which is then digitally processed. The distinguishing features are extracted and a fingerprint biometric template is created. This biometric template is stored and will be used for matching later. The module is capable of 1 : $\mathrm{N}$ matching. The image is buffered and compared to all the stored fingerprints individually. The binary template is processed in the fingerprint module itself and a positive or negative feedback is sent to the microcontroller.

\section{Algorithm For The Fingerprint Sensor:}

Step 1: Load drivers from UART

Step 2: Create function FINGER_ENROL

Step 3: Initialise UART buffer

Step4: LCD = "PLACE YOUR FINGER"

Step 5: Send to UART buffer

Step6: $\mathrm{LCD}=$ "PLACE YOUR FINGER FOR CONFIRMATION"

Step7: Send to UART buffer, match $=1$

Step8: LCD="YOU ARE REGISTERED, THANK YOU"

Step 9: SEL0 for microcontroller.

Step10: Repeat process with flashing program again for more users.

\section{Algorithm For Stepper Motor:}

Step 1: Create 4 functions step_clock, step_clock1, step_anticlock, step_anticlock1

Step 2: Initialize all function components (4 for each)

Step 3: Loop for the case of load_cell_limit reached

Step4: while load_cell=0, set step_clock and step_anticlock for one positions in each

Step5: Delay 50ms after each step

Step6: Next, while load_cell=0, set step_clock1 and step_anticlock1 for one positions in each.

Step7: Delay 50ms after each step

Step8: when load_cell=1, execute step_clock and step_clock1for 50ms Step 9: STOP

Step10: Delay 50ms

Step11: wait for load_cell=0

Step12: REPEAT

\section{RESULTS}

The project prototyped is aimed to design and implement an automatic ration distribution system. According to the prototype designed, on an average a person takes about four minutes to take his/her ration. In our system, we provide wheat and rice in three different weight categories (80g, $100 \mathrm{~g}, 120 \mathrm{~g})$. So, in average fifteen users can get their ration in an hour from the developed prototype. In real time implementation, the total working hours of a normal ration distribution center is about seven hours. Approximately $1 \mathrm{~kg}$ of wheat and $1 \mathrm{~kg}$ of rice can be distributed by the system in eight minutes. So, the system can serve to approximately 52 people in a day. Time taken by each consumer is taken as 4 minutes (for each wheat and grain), if the ration shop is open for 7 hours in a day, then, $60 \mathrm{~min} /($ time for each)= consumers in an hour i.e. $60 /(4+4)=7$ people. The quantity of dispensed material is calculated with every trial and average is calculated in table 5.2 which results in the accuracy of the prototype, calculated as an average $(87+82+79+78) / 4=81.5$. The average accuracy calculated is around $80-85$ percent for 4 trials of weight $100 \mathrm{gm}, 80 \mathrm{gm}, 120 \mathrm{gm}$. The user will be required to authenticate his identity. After the authentication process the user can have access to the updated data of the system. The list of individuals with access to receiving ration consists of a page with details of their ID no, names, email, phone and their place of residence using the username and password provided shown in.

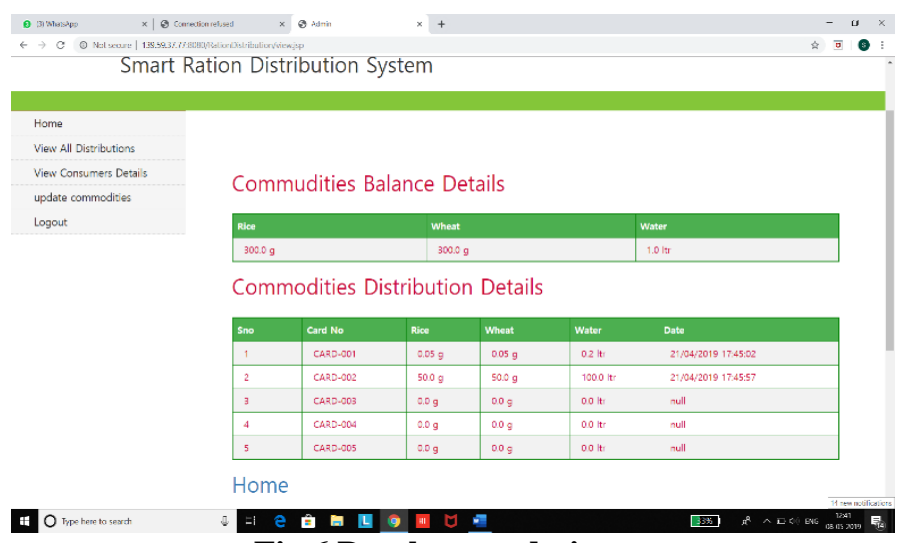

Fig.6 Database updation

The database updation page consists of the balance and distribution details for the commodities. The page is constantly updated in real time as transactions occur to show the balance quantity.

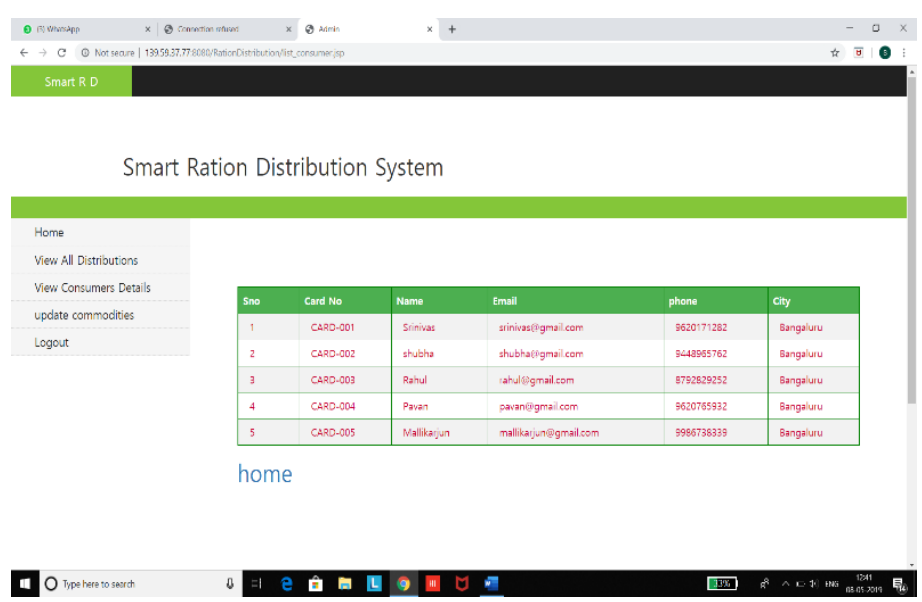

Fig.7 Ration dispensed details

\section{CONCLUSION}

We have designed and developed the automation of the ration dispensing mechanism. Authentication of the user is also taken care of, which helps to avoid the ration being delivered to unintended user. Moreover, the automatic database updating and notification to consumer brings about the transparency in the entire process.

\section{FUTURE SCOPE}

There is potential for further digitalization with the inclusion of android application for the same with similar link to the government server with dynamic tracking of the amount of food grain in every FPS and with a feature of transferring grains from one shop to the other in case of high demand. Attaching all the data received via the system in a fiscal year to the annexures of finance and budget estimation and giving back the community if monetary gain / profit is achieved in terms of discounts and coupons based on performance review of the specific FPS. 


\section{REFERENCES}

1. Government of India NITI Aayog Development Monitoring and Evaluation Office, "Evaluation Study on Role of Public Distribution System in Shaping Household and Nutritional Security India", New Delhi, DMEO Report No. 233, December 2016, pp.2557- 2589.

2. Dr.M.Pallikonda Rajesekaran, D.Balaji, R.Arthi, P.DanieAutomatic Smart Ration Distribution System for Prevention of Civil Supplies Hoarding In India, $20174^{\text {th }}$ IEEE International Conference on Advanced Computing and Communication Systems (ICACCS).

3. Vishnu R. Kale, V. A. Kulkarni, “Object sorting system using robotic arm", International Journal of Advanced Research in Electrical, Electronics and Instrumentation Engineering ,Vol. 2, Issue 7, July 2013, pp. 1567-1836

4. Shubham Mahesh Wari, Mukesh Tiwari, "Smart Public Ration Distribution System", International Journal of Innovative Research in Computer and Communication Engineering Vol. 4, Issue 3, March 2016, pp. 892-989

5. Department of Food \& Public Distribution Ministry of Consumer Affairs, “Annual report 2015-16", Government of India, March 2016, pp. 565-826.

6. Sana A. Qader Perampalli, Dr. R.R. Dube, "Smart Card based e Public Distribution System", International Journal of Advanced Research in Computer and Communication Engineering Vol. 5, Issue 5, May 2016, pp. 0985-1213.

7. Rajesh C. Pingle, P. B. Borole, "Automatic Rationing for Public Distribution System (PDS) using RFID and GSM Module to Prevent Irregularities", HCTL Open International Journal of Technology Innovations and Research, vol. 2 , Mar 2013, pp. 102-111.

8. R.Ramani ,S. Selvaraju, S.Valarmathy, P.Niranjan, "Bank Locker security System Based on RFID and GSM Technology", International Journal of Computer Applications (IJCA) (0975 - 8887) Volume 57No.18, November 2012, pp. 269-286.

9. K. Balakarthik, Closed-Based Ration Card System using RFID and GSM Technology, vol. 2, no. 4, Apr 2013, pp. 8875-9098.

10. Swati R. Zope, Maruti Limkar, "RFID based Bill Generation and Payment through Mobile", International Journal of Computer Science and Network (IJCSN), vol. 1, no. 3, June 2012, pp 6287.

11. S.Sukhumar, K. Gopinathan, S. Kalpanadevi, P. Naveenkumar, N. Suthanthira Vanitha, "Automatic Rationing System Using Embedded System Technology", International Journal of Innovative Research In Electrical Electronics Instrumentation And Control Engineering, vol. 1, no. 8, November 2013, pp 645- 685.

12. Shafi. Mahammad, K. Munidhanalakshmi, "eRation Shop An Automation Tool for Fair Price Shop under the Public Distribution System in the State of Andhra Pradesh", International Journal of Computer Applications, pp 0975-8887.

13. T. Kavitha Rubananth, "GSM based RFID approach to Automatic Street Lighting system", Journal of theoretical and applied information technology, vol. 38, no. 2, april 2012.

14. Parvathy A, Venkata Rohit Raj, Venumadhav, Manikanta, "RFID Based Exam Hall Maintenance System", IJCA Special Issue on "Artificial Intelligence Techniques - Novel Approaches \& Practical Applications" AIT, 2011, pp. 526-544.

15. S.R. Kurkute, D.P. Patil, "Automatic ration distribution system A Review", IEEE conference, June 2011, pp. 114-125.

\section{AUTHORS PROFILE}

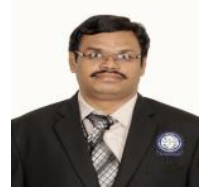

Mallikarjuna Gowda C.P received B.E degree in Electronics and Communication Engineering from Gulbarga University, India. He did his M.E.Tel.E in the field of Communication Engineering from Jadavpur University, Kolkata. Currently Persuing Ph.D in the area of Cognitive Radio Networks from Visvesvaraya Technological University, India. He is currently working as an Associate Professor in the department of Electronics and Telecommunication Engineering at BMS Institute of Technology and Management, Bengaluru. His areas of interest are wireless communication, Cognitive radio networks. He has published research papers in peer reviewed international Journals and presented papers at different National and international Conferences, He reviewed research papers for IEEE Access Journal and IEEE Sponsored International conferences. Life member of Indian Society for Technical Education (ISTE), Solar Energy Society for India (SESI).

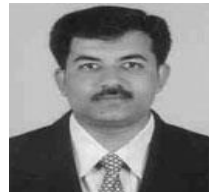

Raju Hajare received B.E degree in Electronics and Communication Engineering from Mysore University, India. He did his M.Tech in the field of Power Electronics from Visvesvaraya Technological University, India. He did his Ph.D in Nano electronics from Visvesvaraya Technological University, India. He is currently working as an Associate Professor in Electronics and Tele Communication Department of BMS Institute of Technology, Bangalore. His areas of interest are Nano electronics, NEMS, Power devices and Robotics. He has Published research papers in reputed peer reviewed international Journals and presented papers at different National and international Conferences. 